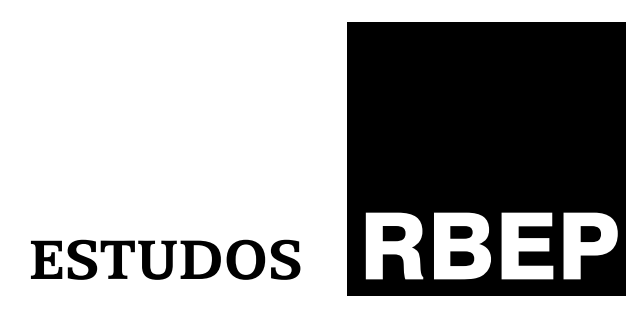

\title{
O trabalho do professor na sala de aula: relações entre sujeitos, saberes e práticas
}

Selva Guimarães Fonseca

\section{Resumo}

Apresenta reflexões sobre resultados de pesquisas que têm como objetivos compreender e analisar os processos pelos quais os sujeitos (formadores e formandos, professores/alunos) se apropriam e reconstroem seus saberes (docentes, escolares, acadêmicos) e práticas, como a formação nos cursos de licenciatura repercute nas ações educativas, na constituição dos saberes e nas (re)configurações curriculares em diversos níveis de ensino. O foco central do texto é a análise de como se dão essas relações entre sujeitos, saberes e práticas e como elas se configuram e impactam o trabalho do professor na sala de aula.

Palavras-chave: trabalho docente; sala de aula; educação básica. 


\section{Abstract \\ The work of the teacher in the classroom: relations among individuals, knowledge and practices}

This article presents reflections about the results of researches that aim to understand and analyze the processes by which individuals (educators and pupils, teachers/students) get and reconstruct their knowledge (teaching, school, academic) and practices; how training in undergraduate courses affects educational activities, the acquisition of knowledge and the curricular (re)configurations at various levels of teaching. The main focus of this paper is to analyze how those relationships between individuals, knowledge and practices actually take place and how they impact teachers' work inside the classroom.

Keywords: teachers work; classroom; elementary school.

Porque aprender-a-viver é que é o viver mesmo...

Guimarães Rosa

\section{Introdução}

Escolhemos este excerto da obra de João Guimarães Rosa para iniciar nossas reflexões acerca do trabalho do professor, pois a sala de aula é, por excelência, um espaço plural, coletivo, o palco no qual professores e alunos/atores/sujeitos vivem, aprendem, ensinam, relacionam-se uns com os outros, com o mundo, com os saberes. Ali eles se expressam, se expõem, se revelam, se colocam por inteiro, na totalidade. Objetividade e subjetividade, corpo e mente, razão e sensibilidade, o bio/psico/social em ação. Na sala de aula, o professor re/constrói sua bio/grafia, sua história, sua trajetória, sua experiência pessoal e profissional. Espaço de aprender e ensinar, logo, um espaço, um campo de relações.

Nesse cenário de construção de experiências, de construção de identidades, capturamos, em lugares diferentes, vozes de duas professoras que nos falam muito: "Eu sei o conteúdo, mas não sei dar aulas!", "Eu gosto de ensinar, mas me falta conteúdo!". A primeira é graduada em História, professora dos anos finais do ensino fundamental em escolas públicas e privadas; a segunda é professora dos anos iniciais do ensino fundamental em uma escola pública.

Essas lastimáveis incoerências podem suscitar diversas indagações acerca das condições de formação e dos seus impactos no trabalho do(a) professor(a), muitas das quais amplamente investigadas e conhecidas no 
meio escolar e acadêmico. Mas, sobretudo, as duas frases nos incitam a pensar, não apenas no que "falta", no "não saber", mas sobre "quem são elas(es)", as(os) professoras(es), o que "sabem", o que "fazem" e "como fazem", como e o que aprenderam em seus percursos formativos. Como se relacionam essas dimensões constitutivas do oficio do professor?

Não sendo possível, neste espaço textual, abordar todos esses problemas, apresentamos algumas reflexões, em diálogo com outras investigações, a respeito de resultados de estudos desenvolvidos em grupo de pesquisa colaborativo que reúne professores formadores em cursos de licenciatura, graduandos, pós-graduandos e professores da educação básica. O objeto central do grupo é a investigação "Formação docente, saberes e práticas de ensino de História", ${ }^{1}$ no que concerne às relações entre sujeitos, saberes e práticas nos processos formativos e na dinâmica do processo de ensino e aprendizagem. Buscamos compreender os processos pelos quais os sujeitos (formadores e formandos, professores/ alunos) se apropriam dos saberes (docentes, escolares, acadêmicos) e práticas e os reconstroem e como a formação (diferentes modalidades, níveis; diferentes tempos e espaços) repercute nas ações educativas, na constituição dos saberes e nas (re)configurações curriculares em diversos níveis de ensino. Questionamos: Como se dão essas relações? Como essas relações entre sujeitos, saberes e práticas se configuram e impactam o trabalho do professor na sala de aula?

Somos sujeitos enredados em um trabalho coletivo de ensino e pesquisa em territórios de formação de professores. Concordamos com Burke (2003, p. 18), para quem, quando produzimos conhecimento e o situamos socialmente, devemos reconhecer que "alguns dos [nossos] vieses, resultados de classe, gênero, nação e geração, sem dúvida ficarão logo aparentes". Logo, esta narrativa contém as marcas de uma experiência pessoal, profissional e acadêmica tecida em um determinado lugar social de produção individual e coletiva.

\section{A formação superior para o trabalho em sala de aula}

Para situarmos o tempo e o espaço dos quais estamos falando, recorremos às análises de Reis (2002) sobre a globalização "como metáfora da perplexidade" e os processos geoeconômicos. Segundo ele, estamos perante tendências e contratendências e temporalidades diversas. Assim, espaço (lugares = identidade, relações sociais e história) e tempo (temporalidades) se cruzam.

Nesse contexto, declara o autor, insistimos na convicção de que a análise das tensões entre mobilidades e localizações não pode ser remetida para a busca das duas faces de uma mesma moeda, o que nos conduz a uma visão apenas dialética. O mais importante, reitera, é a procura das singularidades. A globalização e a localização são processos conflituais e, até, potencialmente independentes. Ambos, mas especialmente a localização, são constitutivos de trajetórias inesperadas (Reis, 2002, p. 106).
${ }^{1}$ Grupo de pesquisa certificado no CNPq e vinculado à linha "Saberes e Práticas Educativas" do Programa de Pós-Graduação em Educação da Universidade Federal de Uberlândia. As pesquisas desenvolvidas pelo grupo têm o apoio da Capes, do CNPq e da Fapemig. 
Para ampliar a compreensão do cenário, recorremos à leitura de Bhabha (2005, p. 19) sobre o nosso tempo e lugar:

(...) nossa existência hoje é marcada por uma tenebrosa sensação de sobrevivência, de viver nas fronteiras do "presente"... Encontramo-nos no momento de trânsito em que espaço e tempo se cruzam para produzir figuras complexas de diferença e identidade, passado e presente, interior e exterior, inclusão e exclusão.

Concordamos com esses autores: vivemos (e sentimos isso no cotidiano) a emergência dos interstícios, sobreposições, deslocamentos, mobilidades, tendências e contratendências. Preocupados com a formação e a prática do professor, servimo-nos de uma das perguntas de Bhabha (2005, p. 20): "Como se formam sujeitos nos 'entrelugares', nos excedentes das partes da diferença?"

Ao defendermos, no ensino de História - reconhecidamente um lugar de fronteira -, as relações entre sujeitos, saberes e práticas, não estamos pensando apenas na pesquisa sobre a formação docente, mas, sobretudo, nas relações entre a formação, a pesquisa, os saberes e as práticas em sala de aula. Estamos ousando pensar nas relações que se estabelecem na sala de aula. A nossa opção é caminhar na intersecção, dialogando com os dois campos: Educação e História. A formação e a prática docente serão discutidas aqui intimamente relacionadas ao conceito de profissionalização, que, por sua vez, envolve, entre outros aspectos, condições de trabalho, carreira regulamentada e formação. Logo, inspirados em Bhabha, ousaremos pensar a formação, os saberes e as práticas nos "entrelugares", articulando passado e presente, nas fronteiras da experiência do ensino e da pesquisa.

Partilhamos as concepções de formação docente, amplamente defendidas nos cenários nacional e internacional, como processo educativo que se desenvolve ao longo da vida dos sujeitos e transcende os limites da escolaridade formal - logo, não se inicia nem termina na educação superior (nos cursos de graduação, pós-graduação e aprimoramento). Processual, permanente, como o processo de aprender e ensinar, desenvolve-se na experiência cotidiana, em diferentes tempos e espaços educativos, como nos espaços de lazer, teatros, cinemas e meios de comunicação, em diferentes lugares de memória, museus, e bibliotecas, em igrejas e sindicatos e nos espaços e atividades formais e informais.

No exercício da profissão, na prática, na experiência da sala de aula, o professor também aprende e se forma. A formação é permanente ecomplexa. A identidade profissional docente é definida social e historicamente. Como é bastante óbvio, não se nasce professor; torna-se professor. É um processo inacabado. O "ser professor" é construído na história de vida, no terreno da experiência pessoal e coletiva em determinados espaços e tempos históricos (Fonseca, 1997; Fonseca, Silva, 2007; Fonseca, Rocha, 2009; Vasconcelos, 2000).

Os cursos superiores de licenciatura são espaços de formação profissional, de aprendizagem da profissão, que possibilitam a articulação 
das atividades de ensino, pesquisa e extensão e as práticas pedagógicas. Como formadores de professores e pesquisadores da área do ensino e aprendizagem de História e professores de Metodologia e Prática de Ensino de História, compartilhamos uma situação para uns dual, interdependente, para outros ambígua, paradoxal, para muitos complexa, pois, como ponderamos anteriormente, situamo-nos em uma região de fronteira, território de disputa de poder no interior da(s) instituição(ões), do(s) curso(s) superior(es) e do próprio meio acadêmico, nos espaços onde se discute a formação docente. Em geral, somos originários de áreas específicas de bacharelado/licenciatura, especializamo-nos em pós-graduação em educação, ensino, e nossas pesquisas têm como objeto/foco problemas do ensino e da aprendizagem. Na estrutura universitária brasileira, sobretudo nas universidades públicas, estamos localizados ou somos alocados (a palavra é esta) em departamentos e/ou faculdades/institutos de educação, programas de pós-graduação e, também, em menor número, em áreas específicas. Essa não é uma situação simples e "natural", como alguns acreditam; em alguns casos é fonte permanente de conflitos e disputas (nem sempre amigáveis).

Pesquisas indicam que a maior parte da produção científica e da pesquisa acadêmica sobre ensino e aprendizagem das áreas específicas desenvolvida nas universidades se realiza nos programas de pós-graduação em educação. Em Minas Gerais, por exemplo, de um total de 43 dissertações e teses que tratam do ensino de História defendidas no período de 1993-2008 nas instituições de ensino superior (IES) localizadas no Estado apenas duas foram produzidas em programas de pós-graduação específicos (Fonseca, Rocha, Silva Junior, 2009). Nos espaços acadêmicos, como as associações científicas, esses profissionais convivem e se movimentam (alguns em terrenos movediços) entre dois lugares institucionalizados (associações e/ou sociedades da área de Educação e demais áreas básicas, como, Biologia, História, Matemática, etc.). Há um terceiro lugar, espaço de afirmação das identidades das áreas, ou seja, as associações e sociedades específicas das áreas do ensino de História, Matemática, Biologia, e assim por diante.

Os lugares, ou como nos sugere Bhabha, os entrelugares que os formadores de professores ocupam nas estruturas institucionais são evidências dos modos de produção de determinadas concepções, crenças, culturas e práticas de formação de professores formadores e de futuros professores. É recorrente, nos cursos de licenciatura específicos - em História, por exemplo -, a crença de que, para ser (bom) professor de História, basta saber História, ou seja, o importante é o domínio do conteúdo da disciplina. Os saberes pedagógicos são considerados complementares, de segunda ordem, de menor importância na hierarquia disciplinar do currículo acadêmico. Muitos professores da chamada "área pedagógica" ou de "ensino" sentem o peso do descaso dos alunos em relação à obrigatoriedade de cursar as disciplinas pedagógicas. Para exemplificar, relembramos vários registros de professores que ouviram seus graduandos/futuros professores denominarem essas disciplinas 
${ }^{2}$ Foram analisadas, por amostra representativa, a estrutura curricular e as ementas de 165 cursos presenciais de instituições de ensino superior, assim distribuídos: 71 de Pedagogia, 32 de Letras: Língua Portuguesa, 31 de Matemática e 31 de Ciências Biológicas (Gatti, Barreto, 2009, p. 117). como "perfumarias". Esse menosprezo é construído socialmente pela desvalorização do trabalho e da profissão do professor, no cotidiano das famílias, no mercado de trabalho, em diferentes espaços de vivência e na própria universidade. Os formadores dessas áreas não são valorizados nem são considerados pesquisadores por muitos. Quantos alunos da universidade estranham o fato de nós, da área do ensino, desenvolvermos projetos de pesquisas aprovados em agências externas à instituição! São também comuns relatos de colegas sobre a dificuldade de alguns cursos para alocarem, entre os professores (que compõem o quadro docente), as disciplinas de Estágio e Prática de Ensino. Isto geralmente ocorre em instituições onde não há contratações de professores específicos e qualificados na área e expressa, a nosso ver, mais uma faceta do desprestígio da formação do professor no interior dos próprios cursos superiores que têm, na universidade, a missão de formar professores.

Pesquisas sobre os currículos das licenciaturas que formam docentes do ensino fundamental evidenciam esses problemas, recorrentes nas diversas áreas e não apenas em História, como mostram os resultados da pesquisa, realizada pelo Departamento de Pesquisas Educacionais da Fundação Carlos Chagas, com apoio da Fundação Victor Civita, Formação de professores para o ensino fundamental: instituições formadoras e seus currículos, coordenada por Bernadete Gatti e Marina Muniz R. Nunes (2008). Nos currículos das licenciaturas analisadas ${ }^{2}$ - Língua Portuguesa, Matemática e Ciências Biológicas -, destacam-se, entre outras, as seguintes características:

- Predomina nos currículos a formação disciplinar específica, em detrimento da formação de professores para essas áreas do conhecimento. $[\ldots]$

- Na maior parte dos ementários analisados, não foi observada uma articulação entre as disciplinas de formação específica (conteúdos da área disciplinar) e as de formação pedagógica (conteúdos da docência).

- Saberes relacionados às tecnologias no ensino estão praticamente ausentes.

$[\ldots]$

- As disciplinas da categoria conhecimentos relativos aos sistemas educacionais registram percentuais inexpressivos de presença em todas as licenciaturas analisadas. [...]. (Gatti, Barreto, 2009, p. 153-154).

Esses problemas impactam de forma significativa o processo de construção dos saberes e das práticas docentes. Pesquisas indicam que a realidade dos cursos superiores de Licenciatura em História é similar às das demais licenciaturas (Mesquita, 1999; Couto, 2004; Moura, 2005; Rassi, 2006; Silva Júnior, 2007). A predominância dos saberes específicos, a desarticulação, a inexpressiva presença dos chamados conteúdos pedagógicos, de estudos relativos ao conhecimento da escola e dos sistemas educacionais são visíveis nas estruturas "grades curriculares", no quadro de horários e na carga horária das disciplinas disponíveis nos sites dos cursos das maiores universidades do País. A pesquisa de Rodrigues 
(2010) sobre os saberes e as práticas de professores iniciantes de História apresenta dados e narrativas que confirmam essa realidade, e, mais do que isso, suscitam-nos indagações sobre o trabalho realizado em sala de aula, como exemplificado pela frase angustiada de uma professora iniciante de História (um a cinco anos de magistério): "Eu sei o conteúdo, mas não sei dar aulas!". ${ }^{3}$

Nos cursos de licenciatura em Pedagogia, o outro lado do "entre", nós, formadores de professores para a educação infantil e anos iniciais do ensino fundamental, vivenciamos (nós, formadores da área do ensino de História) uma cultura acadêmica que valoriza e propaga a crença de que, para ser professor desses níveis de ensino, o importante é o domínio dos saberes pedagógicos, dos fundamentos gerais da educação, das teorias que embasam o ensino, a aprendizagem e, por sua vez, desvalorizam os conteúdos das áreas básicas do currículo escolar: Língua Portuguesa, Matemática, Ciências, História, Geografia, Artes e Educação Física. O exame dos currículos dos cursos de Pedagogia no Brasil são reveladores dessa concepção. Qual o lugar dos profissionais das áreas do ensino nesses cursos? Qual o espaço para o estudo de conteúdos e das metodologias de ensino das áreas básicas, acima mencionadas, nos currículos dos cursos de Pedagogia? Como se dá a formação do professor no campo do ensino e da aprendizagem de conhecimentos das disciplinas da área básica do ensino fundamental? Como se processam o estágio e a prática de ensino na formação dos cursos de Pedagogia?

Gatti e Barreto (2009) apresentam conclusões preocupantes sobre os cursos de Pedagogia - responsáveis pela formação de professores -, algumas delas velhas conhecidas do meio acadêmico, mas enraizadas na cultura acadêmica e institucional. Destacamos:

- O currículo proposto tem uma característica fragmentária, apresentando um conjunto disciplinar bastante disperso.

- A proporção de horas dedicadas às disciplinas referentes à formação profissional específica é de 30\%, ficando $70 \%$ para outro tipo de matérias oferecidas nas instituições formadoras.

- Na análise das ementas das disciplinas de formação profissional predominam os referenciais teóricos, seja de natureza sociológica, psicológica ou outras com associação em poucos casos às práticas profissionais.

- Pode-se inferir que a parte curricular que propicia o desenvolvimento de habilidades profissionais específicas para a atuação nas escolas e nas salas de aula é bastante reduzida.

- Os conteúdos das disciplinas a serem ensinadas na educação básica (Alfabetização, Língua Portuguesa, Matemática, Geografia, Ciências, Educação Física) comparecem apenas esporadicamente; na grande maioria dos cursos analisados, eles são abordados de forma genérica ou superficial no interior das disciplinas de Metodologias e Práticas de Ensino, sugerindo frágil associação com as práticas docentes.

- Os estágios, obrigatórios, são registrados de modo vago, com pouquíssimas exceções. Não há propriamente projeto ou plano de
${ }^{3}$ Depoimento registrado por Rodrigues (2010, p. 25). 
estágio nem sinalizações sobre o campo de prática ou a atividade e a supervisão dos mesmos.

- A escola, enquanto instituição social e de ensino, é elemento quase ausente das ementas, o que leva a pensar numa formação de caráter mais abstrato e pouco integrado ao contexto concreto onde o profissional-professor vai atuar. (Gatti, Barreto, 2009, p. 152-153).

Gatti e Barreto (2009) apresentam uma cartografia e possíveis respostas para muitas das questões acima delineadas. Os currículos dos cursos de Pedagogia são fragmentários; muitos deles (a maioria) não fornecem uma preparação adequada em relação aos conteúdos das áreas básicas do ensino, como evidenciam outras pesquisas, por exemplo, a de Michele Cristina de Moura (2005). Outro aspecto que chama a atenção de muitos formadores das áreas específicas - com experiência na prática de ensino de educação básica - no cotidiano do curso e é retratado nas pesquisas é o caráter abstrato, genérico, da formação. A escola e a sala de aula são elementos "quase ausentes" ou são apresentados de forma descolada da realidade educacional brasileira. Sentimos que paira no ambiente do curso um discurso generalista, vago, desprovido de evidências, muitas vezes estereotipado e até deslegitimador da "escola".

As cargas horárias registradas nas "grades" (o nome é esse mesmo) curriculares de cursos de Pedagogia, disponíveis nos sites de importantes universidades do Brasil, confirmam nossa preocupação com o reduzidíssimo espaço formativo atribuído aos saberes disciplinares, específicos do ensino fundamental.

A "grade das disciplinas do curso de Pedagogia, a partir de 2009", da Universidade de São Paulo (USP), apresenta as seguintes disciplinas correlacionadas: Metodologia do Ensino de Matemática - $5^{\circ}$ semestre, 4 créditos; Metodologia do Ensino de Português: A alfabetização - $6^{\circ}$ semestre, 4 créditos; Metodologia do Ensino de Arte - $7^{\circ}$ semestre, 4 créditos; Metodologia do Ensino de Ciências $-7^{\circ}$ semestre, 4 créditos; Metodologia do Ensino de Educação Física - $8^{\circ}$ semestre, 4 créditos; Metodologia do Ensino de História - $8^{\circ}$ semestre, 4 créditos; Metodologia do Ensino de Geografia - 9o semestre, 4 créditos (USP, 2009).

A "grade curricular do curso de Pedagogia" da Universidade Estadual de Campinas (Unicamp) é similar em relação ao espaço curricular destinado aos conteúdos dos anos iniciais do ensino fundamental, no entanto, as disciplinas são descritas com outras nomenclaturas e com espaço de carga horária para aulas práticas: Escola, Alfabetização e Culturas da Escrita $-5^{\circ}$ semestre, 4 horas teóricas, 2 práticas; Escola e Conhecimento de História e Geografia - 5º semestre, 4 horas teóricas, 2 práticas; Escola e Cultura Matemática - $6^{\circ}$ semestre, 4 horas teóricas, 2 práticas; Escola e Conhecimento em Ciências Naturais - $6^{\circ}$ semestre, 4 horas teóricas, 2 práticas; e Educação, Corpo e Arte $-6^{\circ}$ semestre, 4 horas teóricas, 2 práticas (Unicamp, 2007).

No curso de Pedagogia da Universidade Federal de Uberlândia (UFU), a nomenclatura das disciplinas é a mesma da USP. A carga horária das 
disciplinas é relativamente maior, porém não há espaço para as aulas práticas, como na estrutura da Unicamp, e os conteúdos de Arte e Educação Física não são contemplados como nas outras duas instituições. A grade curricular relaciona as seguintes disciplinas, responsáveis pelos conteúdos e metodologias do ensino: Metodologia do Ensino de Matemática - $1^{\circ}$ ano: $1^{\circ}$ e $2^{\circ}$ semestres, 4 horas teóricas; Metodologia do Ensino de Língua Portuguesa $-1^{\circ}$ ano: $1^{\circ}$ e $2^{\circ}$ semestres, 4 horas teóricas; Alfabetização $-2^{\circ}$ ano: $3^{\circ}$ e $4^{\circ}$ semestres, 3 horas 4 horas teóricas; Metodologia do Ensino de Ciências $-3^{\circ}$ ano: $5^{\circ}$ e $6^{\circ}$ semestres, 4 horas teóricas (UFU, 2009, p. 45-47).

Podemos inferir, com base nas pesquisas e nas descrições anteriores, que a carga horária das disciplinas específicas não varia muito - e é, como evidenciaram Gatti e Barreto (2009) em uma amostra de 71 cursos de Pedagogia, muito inferior à parte do currículo dedicada à formação geral. Assim, nossa percepção é que os docentes polivalentes, nos cursos superiores de Pedagogia, recebem uma formação muito frágil na parte de conteúdos (o que ensinar) e na de metodologias de ensino (como ensinar). Os saberes disciplinares específicos do ensino fundamental são claramente menosprezados em relação à parte de formação geral. Isto nos leva a entender a angústia de uma professora do $3^{\circ}$ ano do ensino fundamental, com sete anos de magistério, que nos afirmou: "Eu gosto de ensinar, mas me falta conteúdo!" (Fonseca, 2003, p. 58) e corrobora, também, resultados de investigação com professoras dos anos iniciais que declaram ensinar História (os conteúdos e as metodologias) do modo como aprenderam quando cursaram o ensino fundamental (Alves, 2008).

Assim, vivenciamos cotidianamente, no interior das instituições, uma situação de relativa desvalorização nos dois campos: na licenciatura em Pedagogia, que oferece um espaço restrito para a atuação dos profissionais "não pedagogos", e, também, nas licenciaturas específicas, em que as disciplinas da área de ensino e a pesquisa sobre o ensino e a aprendizagem são desvalorizadas.

A experiência na docência nos diversos níveis de ensino e na pesquisa sobre o ensino autoriza-nos a preconizar a valorização do diálogo entre as áreas, entre lugares, sujeitos e saberes. Consideramos fundamental uma preparação sólida do professor dos anos iniciais e finais do ensino fundamental, e, para isto, a nosso ver, é imprescindível repensar o lugar dos conteúdos e das metodologias de ensino específicas nesses cursos. Do mesmo modo, avaliamos imprescindível repensar o lugar dos conhecimentos pedagógicos, das metodologias de ensino específicas nos cursos de licenciatura. A nossa proposta, reiterada em outros espaços, é articular ensino, pesquisa e prática pedagógica na graduação, tornando o ensino objeto de investigação nos diversos cursos de licenciatura em parceria com as escolas, campos de estágios e práticas.

A este respeito citamos dois importantes educadores que, em contextos e propósitos singulares, defenderam a importância do conhecimento dos professores. Paulo Freire (2001, p. 2), em carta aos professores brasileiros, 
em 1993, pouco tempo depois de sua experiência na condução da Secretaria de Educação de São Paulo (Seed), afirmou:

\begin{abstract}
O fato, porém, de que ensinar, ensina o ensinante a ensinar um certo conteúdo não deve significar, de modo algum, que o ensinante se aventure a ensinar sem competência para fazê-lo. Não o autoriza a ensinar o que não sabe. A responsabilidade ética, política e profissional do ensinante lhe coloca o dever de se preparar, de se capacitar, de se formar antes mesmo de iniciar sua atividade docente. Esta atividade exige que sua preparação, sua capacitação, sua formação se tornem processos permanentes. Sua experiência docente, se bem percebida e bem vivida, vai deixando claro que ela requer uma formação permanente do ensinante. Formação que se funda na análise crítica de sua prática. (grifos nossos)
\end{abstract}

António Nóvoa (2010, p. 4), educador português com reconhecida produção na área de formação de professores, atualmente reitor da Universidade de Lisboa, destaca em recente entrevista que a análise do trabalho docente nas sociedades contemporâneas deve considerar os seguintes apontamentos: conhecimento, cultura profissional, tato pedagógico, trabalho em equipe e compromisso social; sobre o conhecimento, vale-se das palavras do filósofo francês Alain: "Dizem-me que, para instruir, é necessário conhecer aqueles que se instruem. Talvez. Mas bem mais importante é, sem dúvida, conhecer bem aquilo que se ensina."

Como nos alertam os mestres, se conhecer é fundamental para o exercício do oficio de professor, o curso superior de licenciatura - ainda que seja considerado o "início" da formação profissional - constitui um espaço e um tempo privilegiado para a problematização, produção e aprendizagem de conhecimentos básicos para a constituição do saber docente, da identidade profissional. Portanto, os espaços, os sujeitos formadores e os saberes das áreas específicas e pedagógicas não podem ser tratados e encarados como aqueles de menor prestígio acadêmico no interior das instituições, territórios em permanente disputa, espaços conflituais não aglutinadores. Ao contrário, são interdependentes, relacionais, marcados por singularidades e diferenças constitutivas dos processos educativos, potencialmente construtivos.

\section{A sala de aula como espaço de relações}

Como declaramos na introdução, concebemos a sala de aula como o espaço de aprender e ensinar, logo um espaço, um campo de relações. A nosso ver, os processos e as relações estabelecidas no interior da universidade, como analisados anteriormente, se expressam, de algum modo, no interior da sala de aula, no trabalho do professor, formado em nível superior, em determinados contextos e condições. Em nossas pesquisas, temos buscado investigar as relações entre a formação e as práticas, os sujeitos e os saberes. A formação acadêmica, "longe da escola", faz-se presente "na escola", assim como a mídia, os currículos oficiais, as políticas 
públicas do Estado. Neste sentido, compartilhamos com Charlot (2000, p.78) o seguinte pressuposto: "A relação com o saber (o aprender) é a relação de um sujeito com o mundo, com ele mesmo e com os outros. É relação com o mundo como conjunto de significados, mas também, como espaço de atividades, e se inscreve no tempo."

Esse exercício relacional nos instiga a pensar além das aparentes imbricações entre a formação, o currículo, os saberes e as culturas escolares. Segundo a fértil literatura da área de formação e trabalho docente (Zeichner, 1993, 2002; Ávalos, Nordenflycht, 1999; Tedesco, 1999; Nóvoa, 1992, 2010; Tardif, 2002; Tardif, Lessard, 2005; Contreras, 2002; Gauthier, 1998; Gauthier, Martineau, 2001; Pereira, Zeichner, 2002; Pimenta, Ghedin, 2002; Gatti, Barreto, 2009) e, no caso, de História (Lautier, 1997; Fonseca, 1997; Fonseca, Silva, 2007; Fonseca, Zamboni, 2008), não podemos deixar de reconhecer a heterogeneidade, as singularidades, as histórias de vida, a diversificação, as identidades e as diferenças de professores e alunos no mundo globalizado e multicultural. Na atualidade, não é mais possível mascarar as desigualdades das condições de oferta da educação escolar, no Brasil sobretudo, nem as distinções, por exemplo, de formação escolar e acadêmica; grau de autonomia, de envolvimento institucional; produtividade dos professores; as diferenciações em termos de salários, geração, formação cultural, gênero, religião, etnia e condições de trabalho.

No exercício da prática docente, sabemos que aquilo que o professor ensina ou deixa de ensinar, bem como aquilo que o aluno aprende ou deixa de aprender, vai muito além do proposto nos currículos e livros, materiais didáticos e outros. Sabemos também que não é mera transposição daquilo que foi ensinado nos processos formativos - o que não diminui a responsabilidade dos cursos superiores com a qualidade do trabalho realizado pelo professor na sala de aula - e, certamente, ultrapassa os limites das refratárias culturas escolares. Por isto, defendemos, numa perspectiva socioistórica cultural, um diálogo crítico, permanente, entre os sujeitos (formadores e formandos) que re/constroem saberes e práticas escolares nos diversos espaços educativos e culturais, como a escola de educação básica e as universidades.

O professor não opera no vazio - é óbvio. Mas o que isto significa? A sala de aula é um espaço pleno de experiências. Os saberes, os valores culturais e políticos e os hábitos são transmitidos e reconstruídos na escola por sujeitos históricos, que trazem consigo um conjunto de crenças, significados, valores, atitudes e comportamentos construídos nos vários espaços de vivência, antes e durante o processo de escolarização. Isso tem várias implicações. No campo curricular, como nos ensina Goodson (1995, p. 27) inspirado no historiador inglês Hobsbawn, há necessidade de auscultar, ler o currículo em suas dimensões "prescrito e vivido", como o perfeito exemplo de invenção da tradição. O trabalho do professor produz e reproduz configurações curriculares no jogo de interações que envolvem tensões, conflitos, concessões, vinculações e exclusões. Pesquisas desenvolvidas no nosso grupo (Aguiar, 2006) acerca das relações entre o currículo oficial 
prescrito (de História) e o vivido por professores e professoras em escolas públicas no Estado da Bahia evidenciaram, no fazer histórico da sala de aula, múltiplas tensões, aproximações e distanciamentos entre as duas dimensões curriculares.

De igual maneira, é importante atentarmos para o papel da cultura escolar no trabalho do professor. Se entendermos cultura escolar, como conceitua Juliá (2001, p. 10-11), um "conjunto de normas que definem conhecimentos a ensinar e condutas a inculcar, e um conjunto de práticas que permitem a transmissão desses conhecimentos e a incorporação desses comportamentos", não podemos analisá-la, como complementa o autor, "sem se levar em conta o corpo profissional dos agentes que são chamados a obedecer a essas ordens e, portanto, a utilizar dispositivos pedagógicos encarregados de sua aplicação", ou seja, os professores. Complementamos lembrando Morelo Pintado (2000, p. 226): "as convicções culturais produzidas pela cultura escolar projetam influências sobre os aspectos mais íntimos da sala de aula". O trabalho do professor na sala de aula é permeado, atravessado por múltiplos "fios" explícitos e implícitos - numa urdidura visível e invisível - que repercutem nas ações de ensino e aprendizagem.

Do mesmo modo que as culturas escolares não são uniformes, a ação dos professores na sala de aula é também multiforme, complexa. Antes de recorrer aos nossos referenciais, lembro-me de quando preparava a mesma aula de História (o mesmo tema, a mesma metodologia) para ministrar em quatro turmas de $8^{a}$ série em uma escola pública em uma mesma tarde. Ao final do dia, saía da escola com a certeza de que foram ministradas quatro aulas diferentes em diversos aspectos. Gauthier e Martineau (2001, p. 62-64) sustentam e nos ajudam a entender o argumento da complexidade, com o qual concordamos, recorrendo às seis características identificadas por Doyle e por eles citadas, a saber: multidimensionalidade, simultaneidade, imediatez, imprevisibilidade, visibilidade e historicidade. Lembram-nos, também, os oito tipos de ação, identificados por Tardif (apud Gauthier, Martineau, 2001), "por meio das quais é possível identificar a prática docente: o agir tradicional, o agir afetivo, o agir instrumental, o agir estratégico, o agir normativo, o agir dramático, o agir expressivo e o agir comunicacional". Destacamos o caráter multi ou pluridimensional e a historicidade do trabalho do professor no espaço da sala de aula. O professor não está sozinho, o ensino não é uma tábula rasa, mas, como afirmamos, uma atividade complexa: expressa um conjunto variado, emaranhado e diverso de significados, símbolos, representações e relações, inseridas num espaço social e tempo histórico. Concordando com Gauthier e Martineau (2001, p. 64), todas essas dimensões identificadas pelos autores citados "estão no cerne da prática docente"; logo, no âmbito da instituição educativa, o ensino é uma atividade coletiva, pluridimensional e contextualizada.

O trabalho do professor na sala de aula pressupõe um conjunto de relações entre sujeitos, saberes e práticas. No jogo relacional entre os sujeitos professores e alunos, as pesquisas da área têm focalizado: as relações 
interpessoais; o respeito, a aceitação e a valorização das diferenças entre os alunos; o trabalho em parceria em oposição às relações verticais; a construção da autonomia; a sempre destacada motivação para o estudo, a aprendizagem e o desenvolvimento do prazer de aprender e também de ensinar - vemos aí que as dimensões afetivas e éticas são ressaltadas. No jogo relacional entre sujeitos, saberes e práticas, salientamos a relação teoria-prática, o ensino-pesquisa, a organização do trabalho coletivo, as formas de avaliação e a sempre recomendada postura inter/ multi/transdisciplinar.

O professor, como um dos protagonistas, imbuído do princípio de responsabilidade social inerente ao trabalho coletivo institucional, enfrenta inúmeros desafios no cotidiano escolar. E, no trabalho coletivo, constrói uma cultura profissional, uma identidade, uma história pessoal, singular e, ao mesmo tempo, coletiva, pois partilhada por muitos docentes em diferentes realidades escolares do Brasil. Para Larrosa (1996, p. 464), o modo como nos compreendemos é análogo ao modo como construímos textos sobre nós mesmos, e como são esses textos depende da relação com os outros textos e dos dispositivos sociais nos quais se realizam a produção e a interpretação.

Assim, na atualidade, os desafios da formação, da profissionalização e da ação docente constituem problemas complexos e, neste sentido, demandam políticas sistêmicas capazes de enfrentar as múltiplas dimensões, pois "ser professor", "tornar-se professor", "constituir-se professor" e exercer o ofício é viver a ambiguidade, é exercitar a luta, enfrentar a heterogeneidade, as diferenças sociais e culturais no cotidiano dos diferentes espaços educativos.

\section{Considerações finais}

As fronteiras, os entrelugares, as mediações entre formação e prática e entre sujeitos, saberes e práticas merecem, a nosso ver, ser pensados em movimento, no qual os problemas e as experiências do mundo acadêmico e do cotidiano escolar não se desvinculam, não se descolam do contexto histórico, social, econômico e cultural em que se situam. Precisamos questionar os riscos que podem representar o privilégio, as ênfases ou, em alguns casos, a mitificação da prática escolar como o locus ou a dimensão preferencial da formação do professor, da construção de sua identidade profissional. É necessário compreendermos o caráter singular, complementar/dialógico e dialético dessas relações em cada momento/etapa do processo de formação, de modo que o campo da prática e da crítica não esvazie o científico, o político, o ético e o estético. São dimensões do fazer-se, do processo de construção da identidade profissional. Em outras palavras, não é possível simplesmente substituirmos uma forma de racionalidade por outra.

Portanto, a formação e a atuação do professor em sala de aula são resultantes de múltiplas determinações e relações, de vontades/ 
responsabilidades individuais e coletivas, da obrigação institucional do Estado e da sociedade; logo, devem integrar, de forma ativa e dinâmica, os conhecimentos/as dimensões da experiência, das situações práticas, do mundo acadêmico e da realidade socioistórico e cultural que estamos vivendo. Essas relações são complexas e abertas a uma variedade de interpretações.

\section{Referências bibliográficas}

AGUIAR, Edinalva P. Currículo e ensino de História: entre o prescrito e o vivido - Vitória da Conquista-BA Brasil (1993-2000). 2006. Dissertação (Mestrado em Educação) - Universidade Federal de Uberlândia, Uberlândia, 2006.

ALVES, Raquel E. dos Reis. Os impactos do Projeto Veredas na formação docente, saberes e práticas de ensino de História nos anos/ séries do ensino fundamental. 2008. Dissertação (Mestrado em Educação) - Universidade Federal de Uberlândia, Uberlândia, 2008.

ÁVALOS, B.; NORDENFLYCHT, M. E. La formación de profesores: perspectivas y experiencias. Santiago: Santillana, 1999.

BHABHA, Homi K. O local da cultura. Belo Horizonte: Editora UFMG, 2005.

BURKE, Peter. Uma história social do conhecimento. Rio de Janeiro: Zahar, 2003.

CHARLOT, Bernard. Da relação com o saber. Porto Alegre: Artmed, 2000.

CONTRERAS, J. Autonomia de professores. São Paulo: Cortez, 2002.

COUTO, Regina Célia do. Formação de professores de História e multiculturalismo: experiências, saberes e práticas de formadores(as). 2004. Dissertação. (Mestrado em Educação) - Universidade Federal de Uberlândia, Uberlândia, 2004.

FONSECA, Selva G. Ser professor no Brasil: história oral de vida. Campinas: Papirus, 1997. . Relatório/memorial de formação do Projeto Veredas.

[Belo Horizonte]: SEE, UFU, 2003.

FONSECA, Selva G.; ROCHA, Camila B. Relatório da pesquisa: "O ensino de História na produção científica das IES mineiras (1993-2008)". Uberlândia, 2009. CD ROM. 
FONSECA, Selva G.; ROCHA, Camila B.; SILVA JUNIOR, Astrogildo

F. O que dizem as pesquisas acadêmicas sobre o ensino de História?

(Minas Gerais, 1993-2008). In: ENCONTRO NACIONAL PERSPECTIVAS

DO ENSINO DE HISTÓRIA, 7., 2009, Uberlândia MG. [Anais do VII...].

Uberlândia, MG: Ed. UFU, 2009. v. 1, p. 1-15.

FONSECA, Selva G.; SILVA, Marcos. Ensinar História no século XXI.

Campinas: Papirus, 2007.

FONSECA, Selva G.; ZAMBONI, Ernesta (Orgs.). Espaços de formação de professores de História. Campinas: Papirus, 2008.

FREIRE, P. Carta de Paulo Freire aos professores. Estudos Avançados, São Paulo, v. 15, n. 42, p. 2, maio/ago. 2001.

GATTI, Bernadete A.; BARRETO, Elba S. de Sá (Coords.). Professores do Brasil: impasses e desafios. Brasília: Unesco, 2009. Disponível em: $<$ unesdoc.unesco.org/images/0018/001846/184682por.pdf>.

GATTI, Bernadete A.; NUNES, Marina Muniz R. (Coords). Formação de professores para o ensino fundamental: instituições formadoras e seus currículos - relatório de pesquisa. São Paulo: Fundação Carlos Chagas, Fundação Victor Civita, 2008. 2 v.

GATTI, Bernadete A.; NUNES, Marina Muniz R. (Coords). Formação de professores para o ensino fundamental: instituições formadoras e seus currículos - relatório final: Pedagogia. São Paulo: Fundação Carlos Chagas, 2008. Disponível em: < revistaescola.abril.com.br/fvc/pdf/ bernardete1.pdf>.

GAUTHIER, C. et al. Por uma teoria da Pedagogia. Ijuí: Unijuí, 1998.

GAUTHIER, C.; MARTINEAU, S. Triângulo didático-pedagógico - o triângulo que pode ser visto como um quadrado. Educação nas Ciências, Ijuí, v. 1, n. 1, jan./jun. 2001.

GOODSON, Ivor F. Currículo: teoria e história. Petrópolis: Vozes, 1995.

JULIÁ, Dominique. A cultura escolar como objeto histórico. Revista Brasileira de História da Educação, Campinas, n. 1, p. 9-44, 2001. Disponível em: <www.sbhe.org.br/novo/rbhe/RBHE1.pdf>.

LARROSA, Jorge. La experiencia de la lectura: estudios sobre literatura y formación. Barcelona: Laertes, 1996.

LAUTIER, Nicole. Enseigner l'histoire au lycée. Paris: Armand Colin, Masson, 1997. 
MOURA, Michele Cristina de. Saberes da docência e práticas de ensino de História nos anos iniciais do ensino fundamental. 2005. Dissertação. (Mestrado em Educação) - Universidade Federal de Uberlândia, Uberlândia, 2005.

MESQUITA, Ilka Miglio de. Formação de professores de História: experiências, olhares e possibilidades. 1999. Dissertação (Mestrado em Educação) - Universidade Federal de Uberlândia, Uberlândia, 1999.

NÓVOA, A. (Org.). Os professores e a sua formação. Lisboa: Dom Quixote, Instituto de Inovação Educacional, 1992.

Profissão: docente. Educação [online], São Paulo, n. 154, fev. 2010. Disponível em: <http://revistaeducacao.uol.com.br/ textos.asp?codigo $=12841>$. Acesso em: 13 fev. 2010 .

PEREIRA, Júlio E. D.; ZEICHNER, K. M. (Orgs.). A pesquisa na formação e no trabalho docente. Belo Horizonte: Autêntica, 2002.

. A pesquisa dos educadores como estratégia para construção de modelos críticos de formação docente. In: PEREIRA, Júlio E. D.; ZEICHNER, K. M. (Orgs.). A pesquisa na formação e no trabalho docente. Belo Horizonte: Autêntica, 2002. p. 11-43.

PIMENTA, S. G.; GHEDIN, E. (Orgs.). Professor reflexivo no Brasil: gênese e crítica de um conceito. São Paulo: Cortez, 2002.

PINTADO, Morelo, A. En torno de la cultura escolar como objeto histórico. In: BERRIO, Julio Ruiz (Ed.). La cultura escolar de Europa: tendencias históricas emergentes. Madrid: Editorial Biblioteca Nueva, 2000. p. 223-228.

RASSI, Marco Antônio de Oliveira. Uma canção inacabada: formação de professores de História - a experiência da Fepam (1970-2001). 2006. Dissertação (Mestrado em Educação) - Universidade Federal de Uberlândia, Uberlândia, 2006.

REIS, José. A globalização como metáfora da perplexidade? Os processos geo-económicos e o 'simples' funcionamento dos sistemas complexos. In: SANTOS, Boaventura de S. (Org.). A globalização e as Ciências Sociais. São Paulo: Cortez, 2002. p. 105-132.

RODRIGUES, Heloisa. O peão vermelho no jogo da vida: o professor iniciante de História e a construção dos saberes docentes. 2010. Dissertação (Mestrado em Educação) - Unisinos, São Leopoldo, 2010. 
SILVA JÚNIOR, Astrogildo Fernandes da. Saberes e práticas de ensino de História em escolas rurais. 2007. Dissertação.

(Mestrado em Educação) - Universidade Federal de Uberlândia,

Uberlândia, 2007.

TARDIF, Maurice. Saberes docentes e formação profissional. Petrópolis:

Vozes, 2002.

TARDIF, Maurice; LESSARD, Claude. O trabalho docente. Petrópolis: Vozes, 2005.

TEDESCO, Juan Carlos. Perspectiva internacional sobre los docentes: visión internacional. In: ÁVALOS, B.; NORDENFLYCHT, M. E. La formación de profesores: perspectivas y experiencias. Santiago: Santillana, 1999. p. 14-40.

UNIVERSIDADE DE SÃO PAULO (USP). Faculdade de Educação (FE). Grade das disciplinas do curso de Pedagogia a partir de 2009. Disponível em: < http://www3.fe.usp.br/secoes/inst/novo/graduacao/ pedagogia/pdf/ped_grade.pdf $>$.

UNIVERSIDADE ESTADUAL DE CAMPINAS (Unicamp). Faculdade de Educação. Grade de Pedagogia noturno. In: . Projeto políticopedagógico [do] curso de Pedagogia 2008. Campinas, 2007. p. 33-34. Disponível em: < http://www.fe.unicamp.br/ensino/graduacao/ normas.html>.

UNIVERSIDADE FEDERAL DE UBERLÂNDIA. Divisão de Assuntos Acadêmicos. Guia acadêmico: segundo semestre. 2009. Disponível em: $<$ http://www0.ufu.br/guia_academico $>$.

VASCONCELOS, G. A. N. (Org.). Como me fiz professora. Rio de Janeiro: DPGA, 2003.

ZEICHNER, Kenneth M. A formação reflexiva de professores: idéias e práticas. Lisboa: Educa, 1993.

Para além da divisão entre professor-pesquisador e pesquisador acadêmico. In: GERALDI, C. M. G.; FIORENTINI, D.; PEREIRA, E. M. A. (Org.). Cartografias do trabalho docente: professor(a)-pesquisador(a). Campinas: Mercado de Letras, Associação de Leitura do Brasil, 1998. p. 207-236. 
Selva Guimarães Fonseca, pós-doutora em Educação pela Universidade Estadual de Campinas (Unicamp), é professora da Faculdade de Educação e do Programa de Pós-Graduação em Educação da Universidade Federal de Uberlândia (UFU).

selva@ufu.br

Recebido em 10 de dezembro de 2009.

Aprovado em 14 de abril de 2010. 